\title{
Vision outside the focus of attention
}

\author{
JOCHEN BRAUN and DOV SAGI \\ The Weizmann Institute of Science, Rehovot, Israel
}

\begin{abstract}
We investigated the relationship between focal attention and a feature-gradient detection that is performed in a parallel manner. We found that a feature gradient can be detected without measurable impairment of performance even while a concurrent form-recognition task is carried out, in spite of the fact that the form-recognition task engages focal attention and thus removes attentive resources from the vicinity of the feature gradient. This outcome suggests strongly that certain perceptions concerning salient boundaries and singularities in a visual scene can be accomplished without the aid of resource-limited processes, such as focal attention, and, by implication, that there may exist two distinct perceptual faculties (one attentive, the other not) that are able to bring complementary kinds of visual information simultaneously to our awareness.
\end{abstract}

In certain experimental situations, resources for the processing of visual information appear to become concentrated in one subregion of the field of view. For example, when a precue reveals where in visual space a test target is about to appear, visual performance improves in the cued region well above the performance level elsewhere in the field of view (Eriksen \& Hoffman, 1973, 1974; Hoffman, 1975; Posner, 1980; Posner, Snyder, \& Davidson, 1980; Sagi \& Julesz, 1987). This apparent local accumulation of processing resources is thought to be the consequence of a covert repositioning of visual attention (Julesz, 1981; Neisser, 1967; Treisman \& Gelade, 1980 ), in a process somewhat analogous to overt shifts of eye position.

Another observation thought to concern visual attention derives from experiments with multiple display items. Two or more concurrent visual tasks that concern several test targets separated in visual space are almost always found to interfere with each other (Duncan, 1980, 1984, 1985; Hoffman \& Nelson, 1981; Kröse \& Julesz, 1989; Prinzmetal \& Banks, 1983; Sagi \& Julesz, 1985a), and, in numerous cases, the visual search for a target requires more time when more nontarget items are included in the display (Bergen \& Julesz, 1983a; Dick, Ullman, \& Sagi, 1987; Nakayama \& Silverman, 1986; Quinlan \& Humphreys, 1987; Treisman \& Gormican, 1988). These observations are taken as evidence that visual processing involves, in the situations just described, a limited-capacity stage that is unable to operate simultaneously on multiple display items.

The regional resource accumulation suggested by cuing experiments and the limited-capacity process impli-

This research was supported by grants from Boehringer Ingelheim Fonds and Fritz Thyssen Stiftung to J.B. and from Israel Center for Psychobiology and B. Sheva de Rothschild Foundation to D.S. A brief account of this work has appeared in abstract form (Braun \& Sagi, 1989) and is available as technical report WIS CSS 88-16. Thanks are extended to Shimon Ullman for helpful comments on an earlier manuscript. Requests for reprints may be sent to Dov Sagi, Department of Applied Mathematics, The Weizmann Institute of Science, Rehovot 76100, Israel. cated by multiple-item experiments are thought to reflect the operation of the same process, which has been termed focal attention, spatial attention, or spotlight of attention by various authors. The essential operating characteristic of focal attention is thought to be spatial exclusivity or seriality (i.e., the fact that it cannot operate in more than one region of visual space at a time). The postulate of a unitary process that operates in essentially the same manner in a variety of visual situations has evident heuristic value, although it is, perhaps, not easily justified on empirical grounds. In fact, whether or not the same explanation accounts for both cuing and multiple-item experiments has been questioned (Briand \& Klein, 1987).

The present work concerns the capacity limitation in visual processing that becomes apparent when multiple targets are used and when the visual persistence of a stimulus pattern is limited by masking (Duncan, 1980, 1984, 1985; Hoffman \& Nelson, 1981; Kröse \& Julesz, 1989; Prinzmetal \& Banks, 1983; Sagi \& Julesz, 1985a). Although we see no reason to doubt that this capacity limitation reflects a requirement for focal attention, the postulated unitary perceptual mechanism, many of our conclusions do not depend on, and will be formulated without presuming, the identity of this limited-capacity process with focal attention. The limited-capacity process we study should not be conflated with the more general faculty or faculties of selective attention (Helmholtz, 1850/1925; James, 1890), which permits observers to respond selectively to one particular stimulus, in one particular modality, among the many stimuli that confront our various sensory modalities at all times.

A number of studies have attempted to determine the hypothetical geometrical distribution and manner of movement of focal attention. Several studies agree that the diameter of the region covered by focal attention (i.e., the half width of the profile of visual enhancement) appears to scale with eccentricity and to measure approximately $0.75^{\circ}$ per $1^{\circ}$ of eccentricity (Sagi \& Julesz, 1986; Shulman, Sheehy, \& Wilson, 1986; Shulman, Wilson, \& Sheehy, 1985). However, there are also reports that this 
diameter may vary in a task-dependent manner (Eriksen \& St. James, 1986; LaBerge, 1983; LaBerge \& Brown, 1989; Podgorny \& Shepard, 1983). The time span for which focal attention remains in one place in the field of view can be as brief as 20 to $100 \mathrm{msec}$ (Bergen \& Julesz, 1983a; Sagi \& Julesz, 1985b; Treisman \& Gelade, 1980). It therefore appears that, during one eye fixation, focal attention may be reallocated and rescaled, perhaps several times, to different parts of the visual scene (Eriksen \& Webb, 1989; Murphy \& Eriksen, 1987; Remington \& Pierce, 1984; Sagi \& Julesz, 1985b; Tsal, 1983).

In contrast to the experimental situations described so far, there also exist situations where a limited-capacity process does not contribute to visual performance, at least not in any overt manner. For example, there are many instances where visual search experiments suggest that all items in a display are processed concurrently (Bergen \& Julesz, 1983a; Quinlan \& Humphreys, 1987; Schneider \& Shiffrin, 1977; Shiffrin \& Schneider, 1977; Treisman, 1985; Treisman \& Gelade, 1980). There also appear to be visual tasks for which a precue fails to raise performance (Treisman, 1985) and for which several spatially separate targets can be processed concurrently (Sagi \& Julesz, 1985a), although these findings remain controversial (Duncan, 1984, 1985; Prinzmetal, Presti, \& Posner, 1986).

The concurrent, or parallel, processing of separate regions of visual space has been studied extensively in the context of texture segregation (Beck, 1972; Beck, Prazdny, \& Rosenfeld, 1983; Julesz, 1981, 1984; Neisser, 1967; Treisman, 1985; Treisman \& Gormican, 1988). On the basis of this large body of work, it has been proposed that parallel processing occurs when a visual task relies on simple stimulus features or textons that are registered simultaneously by mechanisms that are scattered across the visual field. The stimulus features in question are thought to be lightness, color, local motion, binocular disparity, aspects of texture, such as local orientation and size (spatial frequency), and perhaps others (Dick, Ullman, \& Sagi, 1987; Julesz, 1981, 1984; Nakayama \& Silverman, 1986; Sagi, 1988; Sagi \& Julesz, 1987; Treisman \& Gelade, 1980). More recently, it has been shown that parallel performance depends on local differences, or gradients, between the features on either side of a texture boundary, or between a singularity and its surroundings (Sagi \& Julesz, 1987). We will refer to tasks based on local feature differences as feature-gradient tasks.

A conceptually different proposal is that parallel processing (automatic detection) prevails for tasks in which targets and nontargets fall into stable and welllearned categories (consistent mapping) (Schneider \& Shiffrin, 1977; Shiffrin \& Schneider, 1977). This view is concerned less with features and other physical aspects of the stimulus than with the plasticity of visual processes in the course of training and with facilitating effects of task anticipation (set).
We have attempted to determine the role of the limitedcapacity process under study (namely, focal attention) in the performance of feature-gradient tasks. In doing so, we were motivated by two considerations. The existence of the local mechanisms that mediate feature-gradient tasks suggests that, collectively, these mechanisms might constitute an independent and distinct perceptual faculty, which might underlie certain specific aspects of visual performance. Furthermore, to understand the limitedcapacity process under study and, if the identification holds, to understand focal attention, it seems important to determine whether this process participates universally in all visual performance or, alternatively, whether it contributes only to some parts of visual function. A general rationale for postulating the existence of several distinct visual faculties or modules has been outlined by Ullman (1984).

With respect to a possible role for a limited-capacity process in parallel performance, two alternatives present themselves. One is that, during parallel performance, resources are dispersed evenly over the entire field of view (Bergen \& Julesz, 1983b; Eriksen \& St. James, 1986; Jonides, 1983; Treisman \& Gormican, 1988). According to this view, processing resources would be distributed over a region of visual space, not among targets, with the consequence that, for targets falling inside this region, performance would be independent of the number of targets. Of course, with processing resources spread more thinly, processing would be limited to relatively undemanding types of targets. If the region in which the limited-capacity process is active can narrow or widen to suit the task at hand, as this view suggests, then serial and parallel visual performance would not mark the two sides of a categorical divide, but merely the opposite ends of continuum.

The second alternative is that the apparatus of the limited-capacity process does not contribute to the performance of feature-gradient tasks; therefore, if the limited-capacity process is identified with focal attention, such performance should be termed nonattentive. In this case, attentive and nonattentive visual processing would constitute distinct perceptual categories and would be performed by two independent visual faculties. Since only one of these would draw on the limited-capacity process, the two faculties might be able to operate concurrently, and perceptions mediated by the two might impinge on awareness roughly simultaneously.

To decide between these alternatives, we performed dual-task experiments in which we asked observers to perform a feature-gradient task together with a second visual task designed to engage the limited-capacity process (i.e., focal attention). We could then study performance of the feature-gradient task with and without the demand on the limited-capacity process posed by the second task. If the limited-capacity process participates in feature-gradient tasks, performance should be impaired when the availability of resources is reduced. In contrast to this expec- 
tation, we found that feature-gradient performance is not measurably affected by load on the limited-capacity process.

A number of authors have previously conducted dualtask experiments under conditions of masking but, in contrast to the present study, did not attempt to combine attentive with nonattentive types of visual tasks (Duncan, 1984, 1985; Kröse \& Julesz, 1989; Sagi \& Julesz, 1985b). The unavailability of attention (inattention) has been found to impair severely the commitment to memory of complex shapes (Rock \& Gutman, 1981). With an intent similar to ours, Hoffman, Nelson, and Houck (1983) studied the role of attentional resources in the detection of automatic targets. These authors chose a digit-among-letters search task under consistent mapping conditions to represent automatic detection (Schneider \& Shiffrin, 1977; Shiffrin \& Schneider, 1977) and a flicker location task to capture focal attention. They found that the two tasks interfere and concluded that "attention shifts apparently play a role in the ability to report target occurrence" (Hoffman, Nelson, \& Houk, 1983, p. 405).

\section{RATIONALE}

For a feature-gradient task, we chose the detection of a target element, differing in orientation from neighboring background elements (Bergen \& Julesz, 1983b; Sagi \& Julesz, 1985a). We took care to create a strong feature gradient by placing background elements densely and by choosing large orientation differences (Sagi \& Julesz, 1987). To ensure that feature-gradient detection was sufficiently demanding to require a significant involvement of a limited-capacity process, if indeed it required any of it, a carefully constructed masking pattern curtailed visual persistence. Because of the masking, this task cannot be described as "easy." In fact, the duration of stimulus persistence required for this task (its psychometric curve) was similar to the attentive tasks with which it was to be combined.

To demonstrate that feature-gradient detection was, under our conditions, performed in a parallel manner, we conducted Experiment 1, in which observers attempted to simultaneously carry out two separate feature-gradient detection tasks, one in the top and one in the bottom half of the display. Another purpose of Experiment 1 was to confirm the practicability of our dual-task procedure (i.e., to show that observers are able to generate two yes/no responses concerning two separate but concurrently presented targets without impairment of performance).

To engage focal attention, we chose an orientation discrimination task. This choice was motivated by recent reports that even simple feature discriminations require access to the limited-capacity stage (Sagi \& Julesz, 1985a, $1985 b$ ). To confirm that this task poses a demand for a limited-capacity process, we conducted Experiment 2, in which observers attempted to simultaneously accomplish two orientation discriminations. The outcome suggested that our orientation-discrimination task engages the limited-capacity process for approximately $50 \mathrm{msec}$.

Next, we addressed the central concern of the present study: the relationship between the limited-capacity process and feature-gradient performance. In Experiment 3, observers attempted to combine the two tasks characterized by the preceding experiments. The results showed that feature-gradient detection and orientation discrimination can be accomplished simultaneously without measurable task interference or performance impairment.

The interpretation favored by us for this outcomethat the resources of the limited-capacity process, and, therefore, of focal attention, do not participate in featuregradient detection-would appear to depend on whether resources of the limited-capacity process were drawn effectively to the target of the orientation discrimination and away from those regions of visual space where featuregradient targets appeared. To increase our confidence in this respect, we conducted Experiment 4, in which the orientation discrimination was replaced by a handedness discrimination, which we hoped would engage the limitedcapacity process even more firmly. The outcome remained unchanged.

\section{METHOD}

\section{Subjects}

Seven practiced psychophysical observers participated. Five were naive as to the purpose of the study.

\section{Apparatus}

Stimulus displays were generated by a Sun 2 minicomputer together with an Imaging Technologies framebuffer on a Conrac black-andwhite raster monitor. The display raster consisted of $256 \times 256$ pixels $\times 8$ bits. Display rate was $50 \mathrm{~Hz}$ noninterlaced. The timing of displays was synchronized to the video signal by the driver of the framebuffer device. In this way, defined display times were obtained despite the (non-real-time) operating system of the host computer. The observers initiated trials by pressing the space bar on a standard terminal keyboard and responded by typing the digits 0 or $I$ on a keyboard. An error elicited feedback from the terminal bell.

\section{Stimulus Patterns}

Stimulus patterns were formed by arranging discrete elements in a hexagonal array, resulting in three concentric shells of elements around a center element (Figures 1A-1D). Elements were generated either with continuous luminance distributions in the shape of Gabor functions (GFs) or, in the stimulus for Experiment 4, as line figures. We used GFs because their spacing in an array does not vary with orientation, as it would for line elements, and because they can be expected to stimulate a more defined population of neural filters (Daugman, 1984; Sagi, 1988).

At the center of Stimulus Patterns B and C (Figure 1), a smaller GF element (center target) assumed an orientation of $0^{\circ}$ or $90^{\circ}$ (horizontal or vertical) with equal probability. At the center of Stimulus Pattern D, there appeared a line element (arrow target). In all stimulus patterns, there sometimes appeared eccentric GF elements (eccentric targets) of $0^{\circ}$ or $90^{\circ}$ (horizontal or vertical) orientation. Either orientation occurred with equal probability. In Stimulus Pattern B, the eccentric targets were always present. Eccentric targets appeared only in the second shell of array positions (i.e., at approximately $3^{\circ}$ of eccentricity). In Stimulus Patterns B, C, and D, 


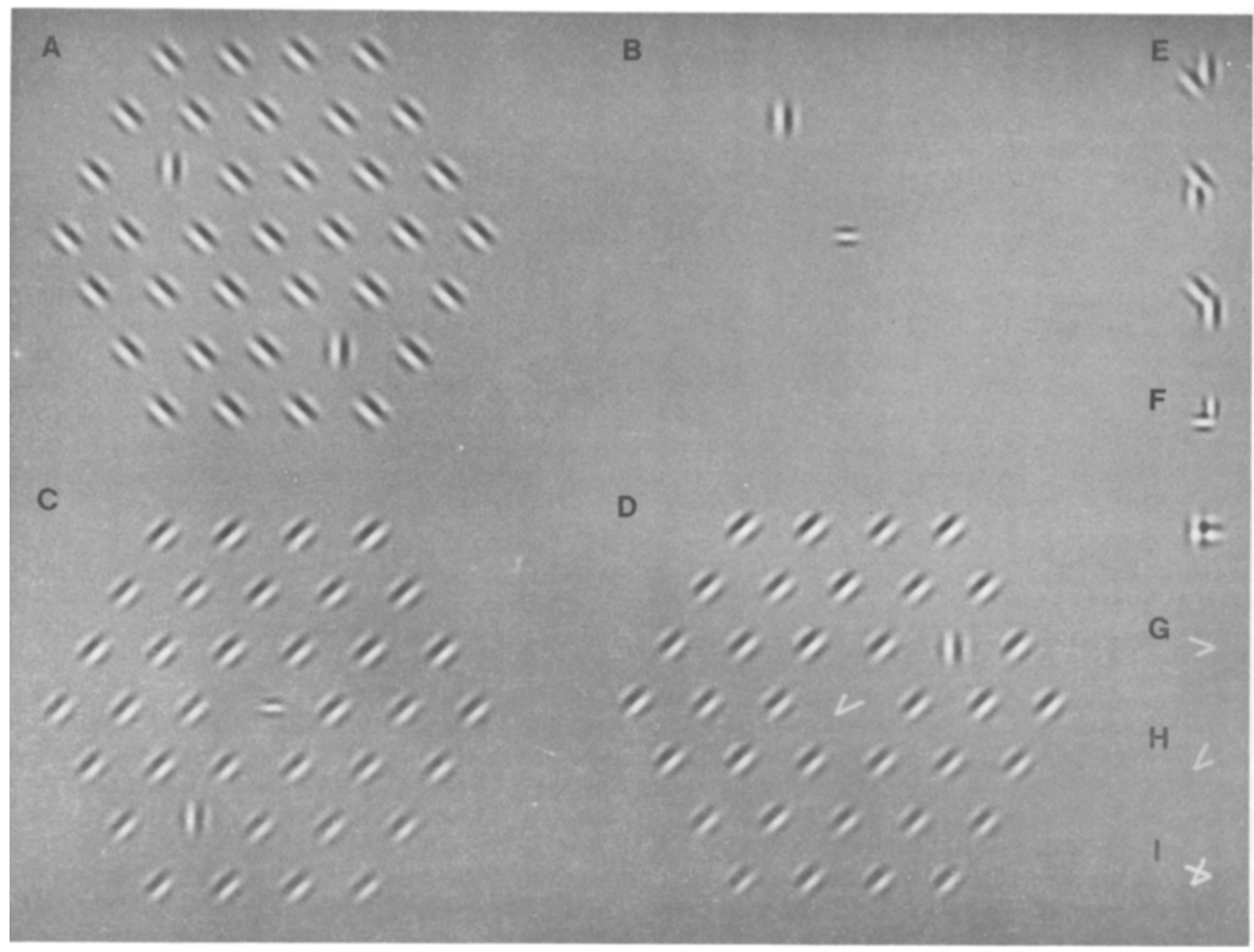

Figure 1. Stimulus patterns, mask elements, and illustration of arrow discrimination task. (A) Stimulus pattern combining two pop-out detection tasks. Two eccentric targets were independently present or absent in the top and bottom halves of the pattern. (B) Two orientation-discrimination tasks. A central target and one eccentric target assumed, independently, horizontal or vertical orientation. (C) Orientation-discrimination task and pop-out detection task. The central target assumed horizontal or vertical orientation and, independently, one eccentric target was present or absent. (D) Arrow discrimination task and pop-out detection task. The central arrow assumed one of two possible mirror-symmetric forms and, independently, one eccentric target was present or absent. (E-F) Typical mask elements for Gabor function elements. (G-I) Dlustration of arrow task: counterclockwise form of arrow target (G), clockwise form of arrow target (H), mask pattern for the arrow target (I).

all 12 positions in the second shell of the array were equally likely to display an eccentric target. In Stimulus Pattern A, eccentric targets were confined to 10 positions in the second shell of the array, since eccentric targets never occurred on the horizontal midline. In Stimulus Patterns A, C, and D, all remaining array positions were occupied by GF elements (background elements) of uniform orientation, chosen to be $45^{\circ}$ or $135^{\circ}$ (diagonal or antidiagonal) with equal probability.

In Stimulus Pattern B, no background elements were used in order to exclude the possibility of any contribution from feature-gradient mechanisms to eccentric-target discrimination.

The handedness target at the center of Stimulus Pattern D (Figure 1D) was formed by two line elements of slightly different lengths $\left(0.35^{\circ}\right.$ and $\left.0.40^{\circ}\right)$, which were joined at a $60^{\circ}$ angle and which assumed two mirror-symmetric forms, as shown in Figure 1G (counterclockwise target) and Figure 1H (clockwise target). Either form of the arrow target appeared with equal probability at $22.5^{\circ}$, $67.5^{\circ}, \ldots, 337.5^{\circ}$ orientation. The handedness target was thus rotated (almost) arbitrarily in the image plane before being displayed.
In every trial, elements were displaced from their exact array positions within the confines of a square whose sides measured one fourth of the nominal element spacing. In addition, element contrast was varied between $80 \%$ and $100 \%$ of nominal contrast. However, displacement and contrast were not set for each element individually. Instead, elements were divided randomly into two groups for which displacement and contrast were determined separately. These measures served a double purpose: (1) they created a large variety of stimulus patterns and prevented the pop-out detection from degenerating into a detection of memorized patterns, and (2) they increased the effectiveness of the mask by rendering unpredictable the spatial relationship between stimulus and mask elements.

Display size was $9^{\circ} \times 9^{\circ}$; mean luminance was $65 \mathrm{~cd} / \mathrm{m}^{2}$; nominal element spacing was $1.2^{\circ}$; spatial periods of GFs were $0.18^{\circ}$ to $0.28^{\circ}$ (center) and $0.35^{\circ}$ (elsewhere); $1 / \mathrm{e}$ radii of GFs were $0.07^{\circ}$ to $0.11^{\circ}$ (center) and $0.25^{\circ}$ (elsewhere); nominal stimulus contrast was $25 \%$ to $36 \%$; nominal mask contrast was twice stimulus contrast. 


\section{Mask Patterns}

Mask patterns were varied on every trial and were formed through one-to-one replacement of stimulus elements by appropriate mask elements. Mask patterns, in contrast to stimulus patterns, were not uniform, since background elements were masked by one of two possible (randomly chosen) mask elements. Mask elements were constructed in such a way as to ensure that a superposition of stimulus and mask element would render the stimulus elements indiscriminable. Mask elements for GF eiements were a superposition of two GFs of different orientation that had been displaced independently from their nominal position in the manner described above. GF mask elements were recomputed for every trial. Typical GF mask elements for Experiments 1, 3, and 4 (Stimuli A, C, and D, Figures $1 A, 1 C$, and ID) are shown in Figure 1E; typical mask elements for Experiment 2 (Stimulus B, Figure 1B) are shown in Figure 1F. The line figure (handedness target) used in Experiment 4 (Stimulus D, Figure 1D), which could appear in one of two mirror-symmetric forms (Figures $1 \mathrm{G}$ and $1 \mathrm{H}$ ), was masked by another line figure, shown in Figure 1I.

\section{Tasks}

Feature-gradient detection. The observers indicated the presence or absence of a GF function element of horizontal or vertical orientation within a dense background of diagonal or antidiagonal elements.

Orientation discrimination. The observers indicated whether a GF target assumed horizontal or vertical orientation.

Handedness discrimination. The observers indicated whether a line-figure target assumed clockwise or counterclockwise form.

\section{Procedure}

Each type of stimulus pattern posed two distinct visual tasks for the observer. Our objective was to determine how well the observer could carry out both tasks of the pattern simultaneously. Accordingly, we conducted with each pattern type a double-task experiment, in which the observer attempted to accomplish both tasks concurrently, as well as two single-task experiments, in which the observer attempted only one of the two tasks. The single-task experiments provided the standard of reference against which doubletask experiments were judged. We wish to emphasize that singletask stimulus patterns contained all targets and target forms, including those irrelevant to the task performed, so that double- and single-task experiments were conducted on identical stimulus ensembles.

Experiments were conducted in blocks of 50 or 100 trials. The observers were instructed to fixate a mark at the center of the video screen before initiating a trial. Fixation was not monitored otherwise. After the observer had signaled readiness, the screen displayed the stimulus pattern (for $20 \mathrm{msec}$ ), then mean luminance (for 0 to $160 \mathrm{msec}$ ), and finally a mask pattern (for $100 \mathrm{msec}$ ). The brevity of the stimulus interval precluded a second fixation. The interval between stimulus and mask onset (stimulus onset asynchrony, or SOA) controlled the visual availability of the stimulus pattern. After trial presentation, the observers responded by typing the digits 0 or 1 on a keyboard. In double-task blocks, the observers gave two such responses, in the order specified in the text. Error feedback from the terminal bell was given in the same order; a delay rendered the second bell tone distinct from the first.

The observers were well practiced and had achieved stable performance during thousands of practice trials prior to each experiment. The serial order in which Experiments 1, 2, 3, and 4 were carried out was balanced across observers. The order of the various SOAs for which data was to be collected was chosen unsystematically. Experimental sessions lasted 1 to $2 \mathrm{~h}$, and were almost always devoted to one particular SOA. However, sessions always included blocks of all three instruction types (the double-task and two single-task instructions), and blocks of the various types were alternated several times during each session.
Performance was measured in terms of the percentage of correct responses, averaged across positive and negative trials, as a function of SOA. The ratio of false positive to false negative responses was analyzed. Although this ratio revealed some observer bias (typically on the order of 0.5 to 2.0 ), it did not vary significantly between double- and single-task conditions. It was therefore deemed unnecessary to report $d^{\prime}$ measures.

\section{Task Synchrony}

Considerable effort went into the design of stimulus-mask combinations that prevented stimulus discrimination (i.e., resulted in chance performance on all tasks) for SOA values below $40 \mathrm{msec}$. All experiments included (without being limited to) SOA values that were insufficient for the reliable performance of the tasks used (performance below $80 \%$ correct). These measures were intended to create conditions under which stimulus patterns were available exactly as long as necessary for the task to be performed, and not longer.

Task performance was limited not by stimulus visibility, but by backwards masking. Without the mask, single and double tasks were performed without error. For a task that presents a demand on a limited-capacity system, masking is expected to favor resourcelimited, rather than data-limited, performance (Norman \& Bobrow, 1975). A second consequence of the use of masking was that, in the double-task situation, the observers were compelled to attempt both tasks synchronously.

\section{Task Difficulty}

For every experiment, the two tasks involved were adjusted (typically, by varying mask contrast) so that they required stimulus persistence for approximately equal spans of time. The SOA at which observers achieved a performance of $75 \%$ correct responses (threshold) was estimated by fitting the psychometric function

$$
P(t)=1-\frac{1}{2} 2^{-(t / T)^{\gamma}}
$$

to each data set. Values for the parameter $\gamma$ ranged from 2 to 5. Values for the threshold parameter, $T$, are listed in Tables 1, 2, 3 , and 4 . The performance values achieved by a given subject in all blocks of trials at a given SOA were averaged to yield the mean performance, and its standard error, at the given SOA. A representative standard error for the data set was obtained as the geometric average of the standard errors at given SOA values. This average was taken over those SOA values for which mean performance lay between $60 \%$ and $90 \%$ correct. A confidence interval for the parameter $T$ was computed from the representative standard error and from the slope of the fitted psychometric function.

\section{RESULTS}

\section{Experiment 1: Combination of Two Feature-Gradient Detections}

The stimulus pattern for Experiment 1 contained up to two eccentric targets that appeared, independently, in one of the top five and/or in one of the bottom five locations in the second shell of the stimulus array (Figure 1A). All possible target positions were equally probable. Thus, eccentric targets appeared in the top and/or bottom halves of the display, never on the horizontal midline, and each half contained either one target or none with equal probability.

In the double-task situation, the observers were asked to devote equal effort to the top and bottom halves of the display and to attempt to detect simultaneously targets in both halves. 

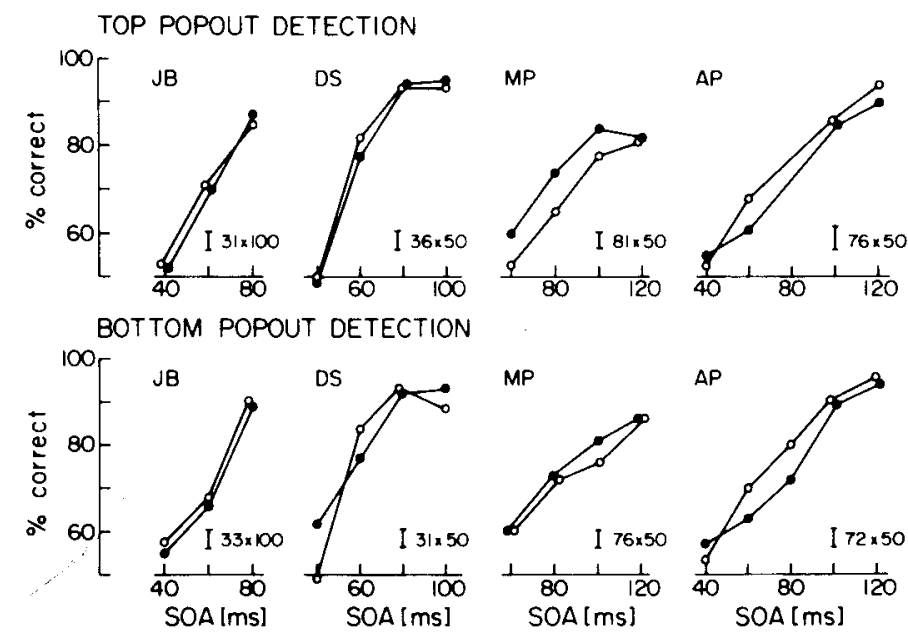

Figure 2. Top and bottom pop-out detection tasks for Observers J.B., D.S., M.P., and A.P. This figure, as well as subsequent ones, represents visual performance (frequency of correct responses) as a function of stimulus availability (stimulus onset asynchrony). Each graph compares performance when the task was carried out alone $(O=$ single-task situation) and performance when the other task of the pair was carried out concurrently $(\bullet=$ double-task situation). At the lower right of each graph are the average standard error, the number of blocks of trials on which the graph is based, and the number of trials per block.

The observers reported on the stimulus by means of two separate present/absent responses-one pertaining to targets in the top half of the display and another pertaining to targets in the bottom half of the display. In the two single-task situations, the observers reported whether or not they had detected a target in one half of the display, and they disregarded the other half (and any target there).

Four observers participated, and the outcome is represented by two graphs per observer-one graph for feature-gradient detection in the top half of the display and another for feature-gradient detection in the bottom half (Figure 2). Graphs are based on 1,550 to 4,050 responses each, as indicated in Figure 2. Each graph contains the task's psychometric curves in both single-task (open circles) and double-task (filled circles) situations. The threshold values computed from this data are listed in Table 1.

The psychometric curves obtained for single- and double-task situations were practically identical. With the exception of a small improvement of Observer M.P.'s performance in the double-task situation, there were no significant differences in the computed threshold values between single- and double-task situations (Table 1). This outcome shows that the two pop-out detections do not hinder each other (even when carried out together they retain the levels of performance at which each is carried out alone) and confirms that our choice for a featuregradient task is performed in a parallel manner. The out-

Table 1

Mean Stimulus Onset Asynchronies (SOAs) and Standard Errors at the Single-Task and the Double-Task Thresholds in Experiment 1

\begin{tabular}{|c|c|c|c|c|c|c|c|}
\hline \multirow[b]{2}{*}{ Observer } & \multicolumn{2}{|c|}{ Single Task } & \multicolumn{2}{|c|}{ Double Task } & \multirow[b]{2}{*}{ Difference } & \multirow{2}{*}{$\begin{array}{c}S E \text { of } \\
\text { Difference }\end{array}$} & \multirow[b]{2}{*}{ Significance } \\
\hline & $M$ & $S E$ & $M$ & $S E$ & & & \\
\hline \multicolumn{8}{|c|}{ Top Detection Task } \\
\hline $\begin{array}{c}\text { J.B. } \\
\text { D.S. } \\
\text { M.P. } \\
\text { A.P. } \\
\text { Average }\end{array}$ & $\begin{array}{r}66.7 \\
63.0 \\
101.9 \\
73.4 \\
76.2\end{array}$ & $\begin{array}{r}3.6 \\
2.3 \\
4.6 \\
4.4 \\
15.3\end{array}$ & $\begin{array}{l}66.8 \\
64.5 \\
89.3 \\
76.3 \\
74.2\end{array}$ & $\begin{array}{l}3.6 \\
1.9 \\
4.5 \\
5.0 \\
9.8\end{array}$ & $\begin{array}{r}0.1 \\
1.5 \\
-13.3 \\
2.9 \\
2.2\end{array}$ & $\begin{array}{l}4.8 \\
3.0 \\
6.5 \\
6.7 \\
6.5\end{array}$ & $\begin{aligned} & \text { n.s. } \\
& \text { n.s. } \\
p & <.025 \\
& \text { n.s. } \\
& \text { n.s. }\end{aligned}$ \\
\hline \multicolumn{8}{|c|}{ Bottom Detection Task } \\
\hline $\begin{array}{c}\text { J.B. } \\
\text { D.S. } \\
\text { M.P. } \\
\text { A.P. } \\
\text { Average }\end{array}$ & $\begin{array}{l}62.0 \\
59.7 \\
94.1 \\
79.9 \\
73.9\end{array}$ & $\begin{array}{r}2.1 \\
3.8 \\
5.7 \\
6.5 \\
14.0\end{array}$ & $\begin{array}{l}65.1 \\
57.6 \\
88.2 \\
82.6 \\
73.4\end{array}$ & $\begin{array}{r}3.3 \\
4.4 \\
4.6 \\
4.5 \\
12.5 \\
\end{array}$ & $\begin{array}{r}3.0 \\
-2.1 \\
-5.9 \\
2.6 \\
-0.6\end{array}$ & $\begin{array}{l}3.9 \\
5.9 \\
7.3 \\
7.9 \\
3.7 \\
\end{array}$ & $\begin{array}{l}\text { n.s. } \\
\text { n.s. } \\
\text { n.s. } \\
\text { n.s. } \\
\text { n.s. }\end{array}$ \\
\hline
\end{tabular}

Note-All values for mean SOAs and SEs are given in milliseconds. 

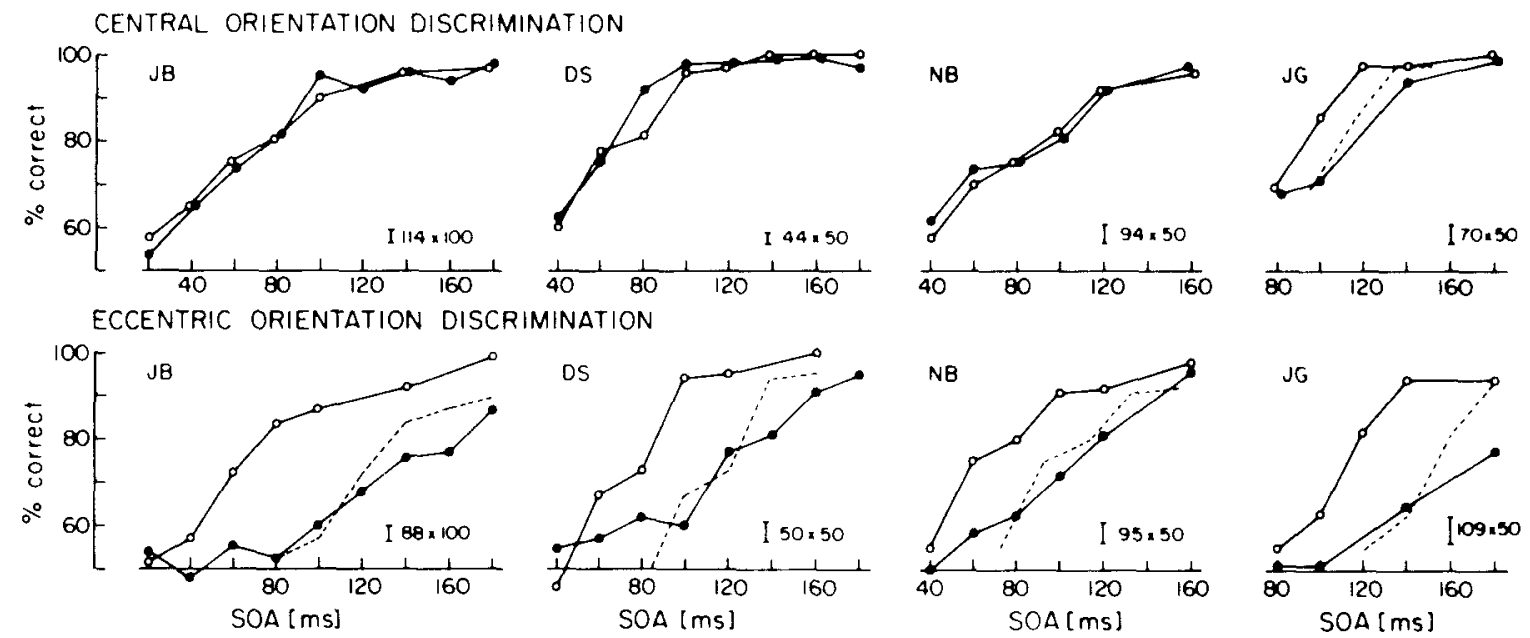

Figure 3. Central and eccentric orientation-discrimination tasks for Observers J.B., D.S., N.B., and J.G. $\odot=$ single-task situation. - double-task situation. The dashed lines are discussed in the text. See Figure $\mathbf{2}$ caption for other details.

come also confirms that observers are able to perform reliably in the double-task situation.

\section{Experiment 2: Combination of \\ Two Orientation Discriminations}

The stimulus for Experiment 2 was composed of just two target elements: one (the center target) appeared at display center, and another (the eccentric target) appeared in one of the 12 positions in the second shell of the stimulus array (Figure 1B). All possible positions of the eccentric target were equally probable. Both the center and the eccentric target assumed independently and with equal probability either a horizontal or a vertical orientation.

Background elements were not used in order to exclude any contribution of feature-gradient mechanisms to the discrimination of the eccentric target. ${ }^{1}$ The asymmetric placement of the targets (one central, the other eccentric) reproduced the target positions in Experiments 3 and 4.
As it turned out, the absence of background elements resulted in two tasks with almost equal psychometric curves, thus approximating the symmetric conditions (two eccentric targets) of Experiment 1.

In the double-task situation, the observers produced two vertical/horizontal responses-the first one pertaining to the center target and the second one pertaining to the eccentric target. To maintain double- and single-task performance on the center target at comparable levels, the observers were instructed to give priority to the discrimination of the center target in the double-task situation. Identical instructions were used in Experiments 3 and 4. The use of a task ranking simplified analysis of the outcome, because it ensured optimal, or almost optimal, performance on the primary task and therefore limited our observations to a one-dimensional subset of twodimensional domain that describes the performance tradeoff between two limited-capacity tasks (Norman \&

Table 2

Mean Stimulus Onset Asynchronies (SOAs) and Standard Errors at the Single-Task and the Double-Task Thresholds in Experiment 2

\begin{tabular}{|c|c|c|c|c|c|c|c|}
\hline \multirow[b]{2}{*}{ Observer } & \multicolumn{2}{|c|}{ Single Task } & \multicolumn{2}{|c|}{ Double Task } & \multirow[b]{2}{*}{ Difference } & \multirow{2}{*}{$\begin{array}{c}S E \text { of } \\
\text { Difference }\end{array}$} & \multirow[b]{2}{*}{ Significance } \\
\hline & $M$ & $S E$ & $M$ & $S E$ & & & \\
\hline \multicolumn{8}{|c|}{ Central Discrimination Task } \\
\hline $\begin{array}{c}\text { J.B. } \\
\text { D.S. } \\
\text { N.B. } \\
\text { J.G. } \\
\text { Average }\end{array}$ & $\begin{array}{l}62.6 \\
62.5 \\
76.6 \\
86.8 \\
72.1\end{array}$ & \begin{tabular}{r|}
4.8 \\
5.2 \\
5.7 \\
3.4 \\
10.2
\end{tabular} & $\begin{array}{r}61.9 \\
57.3 \\
69.5 \\
101.9 \\
72.6\end{array}$ & $\begin{array}{r}7.7 \\
2.0 \\
5.3 \\
4.3 \\
17.4\end{array}$ & $\begin{array}{r}-0.7 \\
-5.2 \\
-7.1 \\
15.1 \\
0.5\end{array}$ & $\begin{array}{l}9.1 \\
5.6 \\
7.8 \\
5.5 \\
8.7\end{array}$ & $\begin{array}{l}\text { n.s. } \\
\text { n.s. } \\
\text { n.s. } \\
p<.005 \\
\text { n.s. }\end{array}$ \\
\hline \multicolumn{8}{|c|}{ Eccentric Discrimination Task } \\
\hline $\begin{array}{c}\text { J.B. } \\
\text { D.S. } \\
\text { N.B. } \\
\text { J.G. } \\
\text { Average }\end{array}$ & $\begin{array}{r}74.1 \\
79.1 \\
63.2 \\
113.2 \\
82.4\end{array}$ & $\begin{array}{r}6.9 \\
3.9 \\
3.7 \\
3.7 \\
18.7 \\
\end{array}$ & $\begin{array}{l}145.5 \\
117.9 \\
105.3 \\
168.9 \\
134.4\end{array}$ & $\begin{array}{r}6.9 \\
9.8 \\
6.3 \\
8.0 \\
24.7 \\
\end{array}$ & $\begin{array}{l}71.4 \\
38.9 \\
42.2 \\
55.8 \\
52.1\end{array}$ & $\begin{array}{r}9.7 \\
10.5 \\
7.3 \\
8.8 \\
12.8 \\
\end{array}$ & $\begin{array}{l}p<.001 \\
p<.001 \\
p<.001 \\
p<.001 \\
p<.001\end{array}$ \\
\hline
\end{tabular}

Note-All values for mean SOAs and $S E$ s are given in milliseconds. 

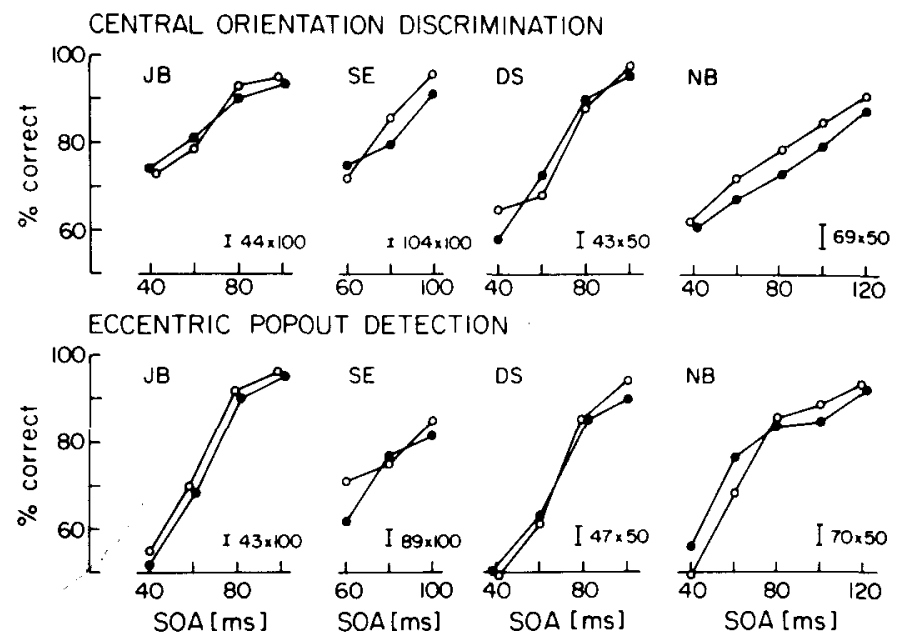

Figure 4. Central orientation-discrimination task and eccentric pop-out detection task for Observers J.B., S.E., D.S., and N.B. $O=$ single-task situation. - = double-task situation. See Figure 2 caption for other details.

Bobrow, 1975). However, during practice trials, we established that the basic outcome of the experiment (task interference) is also obtained if no task ranking is used.

In the single-task situations, the observers produced one response and disregarded the irrelevant target. In a given block of trials, the observers knew which half of the array would be relevant and, occasionally, they might have fixated above or below the display center. A bias large enough to affect performance is not consistent with the outcome of Experiment 2.

The psychometric curves obtained from 4 observers are shown in Figure 3; the threshold values computed from this data are listed in Table 2. Graphs are based on 2,200 to 11,400 responses each. All observers except J.G. were able to follow the instructions concerning the priority of the center target and discriminated the orientation of this target equally well in the double- and single-task situations (Table 2). However, performance on the eccentric target in the double-task situation suffered a highly significant reduction for all observers (Table 2). This inability to simultaneously discriminate two separate targets is what is expected of a task that requires the participation of focal attention.

To quantify the obstacle that the center task appears to pose for the performance of the eccentric task, we displaced the eccentric single-task psychometric curve along the SOA axis until its threshold SOA coincided with the threshold SOA of the double-task curve. This displacement, shown by dashed lines in Figure 3, might be regarded as an effective delay that is imposed on eccentric performance by the double-task situation. Averaged over observers, this apparent delay was $52 \mathrm{msec} \pm 12$ (Table 2). We note that, because the observers were able to carry out the secondary task when the SOA was large enough, it appears more appropriate to describe the outcome in terms of a performance delay than in terms of

Table 3

Mean Stimulus Onset Asynchronies (SOAs) and Standard Errors at the Single-Task and the Double-Task Thresholds in Experiment 3

\begin{tabular}{|c|c|c|c|c|c|c|c|}
\hline \multirow[b]{2}{*}{ Observer } & \multicolumn{2}{|c|}{ Single Task } & \multicolumn{2}{|c|}{ Double Task } & \multirow[b]{2}{*}{ Difference } & \multirow{2}{*}{$\begin{array}{c}S E \text { of } \\
\text { Difference }\end{array}$} & \multirow[b]{2}{*}{ Significance } \\
\hline & $M$ & $S E$ & $M$ & $S E$ & & & \\
\hline \multicolumn{8}{|c|}{ Central Discrimination Task } \\
\hline $\begin{array}{c}\text { J.B. } \\
\text { S.E. } \\
\text { D.S. } \\
\text { N.B. } \\
\text { Average }\end{array}$ & $\begin{array}{l}43.5 \\
64.7 \\
61.0 \\
67.6 \\
59.2\end{array}$ & $\begin{array}{l}2.6 \\
1.7 \\
5.3 \\
7.5 \\
9.4\end{array}$ & $\begin{array}{l}38.1 \\
64.7 \\
62.1 \\
80.3 \\
61.3\end{array}$ & $\begin{array}{r}2.2 \\
2.3 \\
5.5 \\
7.7 \\
15.1\end{array}$ & $\begin{array}{r}-5.3 \\
0.0 \\
1.1 \\
12.7 \\
2.4\end{array}$ & $\begin{array}{r}3.5 \\
2.2 \\
7.8 \\
10.8 \\
6.5\end{array}$ & $\begin{array}{c}p<.10 \\
\text { n.s. } \\
\text { n.s. } \\
\text { n.s. } \\
\text { n.s. }\end{array}$ \\
\hline \multicolumn{8}{|c|}{ Eccentric Detection Task } \\
\hline $\begin{array}{c}\text { J.B. } \\
\text { S.E. } \\
\text { D.S. } \\
\text { N.B. } \\
\text { Average }\end{array}$ & $\begin{array}{l}63.8 \\
82.0 \\
76.9 \\
75.5 \\
74.6\end{array}$ & $\begin{array}{l}1.9 \\
4.0 \\
4.0 \\
4.3 \\
6.7\end{array}$ & $\begin{array}{l}66.4 \\
72.6 \\
73.4 \\
68.8 \\
70.3\end{array}$ & $\begin{array}{l}1.9 \\
5.8 \\
5.5 \\
6.0 \\
2.8\end{array}$ & $\begin{array}{r}2.6 \\
-9.4 \\
-3.5 \\
-6.6 \\
-4.2\end{array}$ & $\begin{array}{l}2.7 \\
7.0 \\
7.0 \\
7.4 \\
4.5\end{array}$ & $\begin{array}{l}\text { n.s. } \\
p<.10 \\
\text { n.s. } \\
\text { n.s. } \\
\text { n.s. }\end{array}$ \\
\hline
\end{tabular}

Note-All values for mean SOAs and SEs are given in milliseconds. 
CENTRAL ARROW DISCRIMINATION
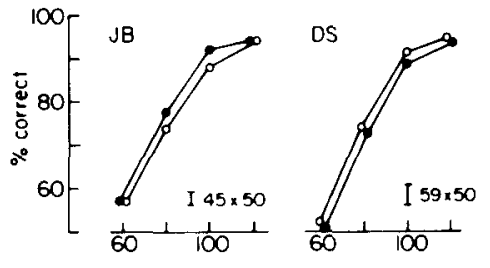

ECCENTRIC POPOUT DETECTION

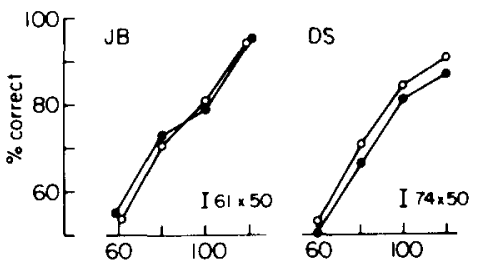

Figure 5. Central arrow discrimination task and eccentric popout detection task for Observers J.B. and D.S. $O=$ single-task situation. $\bullet=$ double-task situation. See Figure 2 caption for other details.

a reduction. If the apparent delay of the secondary task when observers carry out the central discrimination is, in fact, caused by a temporary unavailability of the limited-capacity process at eccentric locations, then this unavailability would seem to persist for approximately $50 \mathrm{msec}$.

\section{Experiment 3: Combination of Pop-Out Detection and Orientation Discrimination}

The stimulus pattern for Experiment 3 contained a central target, which assumed horizontal or vertical orientation with equal probability, and an eccentric target embedded in a background of diagonal or antidiagonal elements (Figure 1C). The eccentric target was present or absent with equal probability and could appear in any one of the 12 positions in the second shell of the stimulus array. The orientation of the eccentric target was horizontal or vertical with equal probability.

In the double-task situation, the observers were asked to attempt to discriminate simultaneously the orientation of the center target and to detect the presence or absence of an eccentric target. As in Experiment 2, the observers were instructed to give priority, and to respond first, to the center target. In single-task situations, the observers were asked to disregard the irrelevant target.

The outcome of Experiment 3, in which 4 observers participated, is shown in Figure 4 and Table 3. Graphs are based on 2,150 to 10,400 responses each. For all observers, single- and double-task performance curves are close to identical on both tasks. On the central discrimination task, there was a weakly significant improvement in the double-task performance of Observer J.B., and a weakly significant reduction for Observer N.B. On the eccentric detection task, there was a weakly significant improvement in the double-task performance of Observer S.E. Accordingly, feature-gradient detection was not measurably affected by the concurrent orientationdiscrimination task, despite the demanding nature of this task vis-à-vis a limited-capacity process. This suggests that the limited-capacity process is not required for the performance of a feature-gradient detection task.

\section{Experiment 4: Combination of Pop-Out \\ Detection and Arrow Discrimination}

Experiment 4 was exactly analogous to Experiment 3, except that a discrimination between two mirrorsymmetric forms of a line-figure target was used instead of an orientation discrimination at the center of the display (Figure 1D). The handedness target assumed clockwise or counterclockwise form with equal probability and, in addition, was rotated randomly in the image plane (see Method section). The task, which after some days of practice could be performed without much mental effort, consisted in discriminating the clockwise and counterclockwise forms of the target. An experiment combining two handedness discriminations (on the strength of a reasoning similar to that followed in Experiment 2) suggested that a central handedness discrimination engages focal attention for approximately $80 \mathrm{msec}$.

Two observers participated, and the outcome is given in Figure 5 and in Table 4. Graphs were based on 2,250 to 3,700 responses each. Observer J.B. showed a weakly significant improvement in his double-task performance of the discrimination task, whereas Observer D.S. displayed a weakly significant reduction in his performance of the detection task. No performance reduction comparable to that of Experiment 2 was observed. As in Experi-

Table 4

Mean Stimulus Onset Asynchronies (SOAs) and Standard Errors at the Single-Task and the Double-Task Thresholds in Experiment 4

\begin{tabular}{|c|c|c|c|c|c|c|c|}
\hline \multirow[b]{2}{*}{ Observer } & \multicolumn{2}{|c|}{ Single Task } & \multicolumn{2}{|c|}{ Double Task } & \multirow[b]{2}{*}{ Difference } & \multirow{2}{*}{$\begin{array}{c}S E \text { of } \\
\text { Difference }\end{array}$} & \multirow[b]{2}{*}{ Significance } \\
\hline & $M$ & $S E$ & $M$ & $\overline{S E}$ & & & \\
\hline \multicolumn{8}{|c|}{ Central Discrimination Task } \\
\hline $\begin{array}{c}\text { J.B. } \\
\text { D.S. } \\
\text { Average }\end{array}$ & $\begin{array}{l}86.7 \\
85.2 \\
86.0\end{array}$ & $\begin{array}{l}3.1 \\
3.5 \\
0.7\end{array}$ & $\begin{array}{l}80.7 \\
87.8 \\
84.2\end{array}$ & $\begin{array}{l}3.3 \\
2.0 \\
3.6\end{array}$ & $\begin{array}{r}-6.0 \\
2.5 \\
-1.8\end{array}$ & $\begin{array}{l}4.5 \\
4.0 \\
4.3\end{array}$ & $\begin{array}{c}p<.10 \\
\text { n.s. } \\
\text { n.s. }\end{array}$ \\
\hline \multicolumn{8}{|c|}{ Eccentric Detection Task } \\
\hline $\begin{array}{c}\text { J.B. } \\
\text { D.S. } \\
\text { Average }\end{array}$ & $\begin{array}{l}90.3 \\
89.0 \\
89.7\end{array}$ & $\begin{array}{l}3.4 \\
5.3 \\
0.7\end{array}$ & $\begin{array}{l}88.8 \\
97.2 \\
93.0\end{array}$ & $\begin{array}{l}4.5 \\
2.9 \\
4.2\end{array}$ & $\begin{array}{r}-1.4 \\
8.2 \\
3.4\end{array}$ & $\begin{array}{l}5.6 \\
6.0 \\
4.8\end{array}$ & $\begin{array}{l}\text { n.s. } \\
p .10 \\
\text { n.s. }\end{array}$ \\
\hline
\end{tabular}

Note-All values for mean SOAs and $S E$ s are given in milliseconds. 
ment 3, the pop-out detection task continued to be carried out essentially at single-task performance levels, even though the limited-capacity process was engaged at fixation by the arrow discrimination.

\section{DISCUSSION}

We have investigated the compatibility of visual tasks that are attempted concurrently. Our procedure included a mask to limit the temporal availability of the stimulus, as well as separate reporting for each task. Under such conditions, the compatibility of two visual tasks that concern targets in separate parts of the field of view is expected to be curtailed by a limited-capacity stage of visual processing (which we believe to be focal attention). Although interference between tasks has been reported previously for similar conditions (Duncan, 1985; Hoffman, Nelson, \& Houck, 1983; Kröse \& Julesz, 1989), we have observed the full compatibility of certain task combinations. Our interpretation of this outcome is that the observed lack of interference is a consequence of our use of a feature-gradient task (i.e., of a target that is embedded in a dense and uniform background). This interpretation is consistent with a large body of work on texture segregation that implicates the existence of nonattentive mechanisms that register local feature differences in parallel across the field of view (e.g., Beck, Prazdny, \& Rosenfeld, 1983; Julesz, 1981, 1984).

That our experimental procedure was suited to reveal interference between two visual tasks was confirmed by a control experiment (Experiment 2) in which substantial task interference was observed. In fact, the outcome obtained in Experiment 2 was consistent with complete interference (i.e., with strictly sequential task performance).

\section{Detection/Localization Task}

The feature-gradient task used here involved a dense array of elements of uniform orientation within which an individual target element of different orientation was embedded. ${ }^{2}$ The task consisted of detecting the presence of such a target in one or two specified regions of the display (the top and bottom halves in Experiment 1, and the entire display in Experiments 3 and 4). Experiment 1 showed that two such detections can be performed concurrently in two regions of the field of view. The performance observed when the task was carried out concurrently in two regions was comparable to the performance obtained when a target had to be detected in only one region of the display.

Studies on texture segregation have given rise to the notion that feature gradients are registered in parallel across the field of view (e.g., Bergen \& Julesz, 1983a). It has been shown that several feature-gradient targets can be detected, counted, and localized concurrently (Sagi \& Julesz, 1985b). Experiment 1 confirms these results and extends them to situations in which observers report the presence or absence of each target separately.

In addition to confirming the parallelism of featuregradient registration, the outcome of Experiment 1 has another implication. It shows that, if performance of such tasks is limited at all by the availability of a limited resource (in the sense of Norman \& Bobrow, 1975), then the allocation of this resource cannot, in this case, be spatially selective. Accordingly, if an attentive process participates in the performance of feature-gradient tasks, it would have to participate in the form of dispersed, rather than focal, attention. This argument has been made by a number of authors who have interpreted parallelism as evidence for a dispersed form of attention (Bergen \& Julesz, 1983b; Eriksen \& St. James, 1986; Jonides, 1983; Treisman \& Gormican, 1988).

It is instructive to compare an experiment reported by Duncan (1985). In the experiment of Duncan, observers monitored simultaneously four locations at which line targets appeared in one of two forms (vertical and tilted). The locations were grouped into pairs, and the more rare target form (tilted) could occur at not more than one location of each pair. The task was to detect the presence of tilted targets concurrently at both pairs of locations. Masking and separate reporting were both used. The outcome was that the detection of a target at one location pair interfered with detecting targets at the other pair of locations. Although there are several differences between this experiment and ours, it is tempting to ascribe the contrasting outcomes to the the fact that the targets of Duncan, although comparable in size to ours, were not embedded in a dense background and were separated from their (two) nearest neighbors by approximately $2.5^{\circ}$. Thus, it is possible that spurious gradients generated by nontargets interfered with target detection. Our targets and background elements were separated by $1.2^{\circ}$ from (six) adjacent background elements, a value that is close to optimal for the detection of feature gradients (Sagi, in press; Sagi \& Julesz, 1987). The possibility that stimulus geometry is the critical difference between the two paradigms is currently under investigation.

\section{Discrimination Tasks}

Our other two tasks required the observer to discriminate between two equally probable forms of a target element. One task involved a discrimination between horizontally and vertically oriented targets; the other involved a discrimination between clockwise and counterclockwise forms of a handed target.

In Experiment 2, two orientation targets were shownone at fixation and another at randomly chosen locations of $3^{\circ}$ of eccentricity. These target locations were identical to the target locations in Experiments 3 and 4 . The outcome showed that the orientations of the two targets could not be discriminated concurrently with the same reliability as each target orientation could be discriminated 
alone. Analogous experiments with handedness targets and with combinations of orientation and handedness targets yielded similar results. ${ }^{3}$

This shows that the performance of these tasks involves a process that is unable to operate on two targets concurrently (i.e., a limited-capacity process). It seems safe to identify this process, whose participation in a visual task has been previously reported to result in competition between spatially separated targets (Duncan, 1980, 1985; Hoffman, Nelson, \& Hough, 1983; Kröse \& Julesz, 1989; Sagi \& Julesz, 1985b), with focal attention, spatial attention, or the spotlight of attention (i.e., with the postulated unitary process thought to account for serial visual processing in a number of situations).

In Experiments 2, 3, and 4, the discrimination of a target at display center was designated as the primary task of the observer. It should be stressed that competition between targets does in no way depend on the imposition of such a task ranking (Braun \& Sagi, 1990; Duncan, 1980, 1985; Sagi \& Julesz, 1985b). Due to this instruction, the primary task was performed, in combination with the secondary one, at, or almost at, the level at which it was performed as a single task. In other words, we observed not impaired performance for both tasks, but a secondary-task performance that was substantially reduced, reflecting the extent to which a limited capacity necessary for task performance was engaged (monopolized) by the primary task, which was being executed in a normal manner.

In combination with the primary task, performance of the secondary task reached a normal level (i.e., the level at which it was performed alone) only if the stimulus was permitted to persist for some additional time. It appears significant that this time (approximately $50 \mathrm{msec}$ for orientation targets and $80 \mathrm{msec}$ for arrow targets) was comparable in magnitude to the SOA (and therefore, presumably, the stimulus persistence time) required by the primary task. The delay observed in the performance of the secondary task was therefore roughly what would be expected from a limited-capacity process that engages the primary target first and the secondary target only thereafter. Whether or not this interpretation is correct, it is clear that the execution of our discrimination tasks poses a large, and possibly exclusive, demand on the resources of a limited-capacity process (which we identify with focal attention). This implies that the performance of these tasks should interfere with the concurrent performance of any other visual task that requires the participation of focal attention (or the limited-capacity process in question) to any significant extent.

\section{Combination of Discrimination and Detection Tasks}

In Experiments 3 and 4, The observers attempted to combine the discrimination and detection tasks described above. The primary task was to discriminate the orientation (vertical or horizontal), in Experiment 3, or handedness (clockwise or counterclockwise), in Experiment 4, of a target at display center. In both Experiments 3 and 4 , the secondary task was to detect the presence of a target of singular orientation within a dense array of uniformly oriented background elements.

The outcome was identical in both experiments: Performance of the secondary task was not affected by the concurrent execution of the primary task. Our interpretation of this outcome is that the secondary task, a featuregradient task, makes no use of the resources of the limitedcapacity process suspected to be focal attention. Before this interpretation-which, if correct, would have important implications for the understanding of visual processing-can be accepted, a number of possible objections must be considered.

\section{Could the outcome reflect difficulties at the level of response selection?}

The first objection is that the interference or noninterference that we observed for various task combinations may have been a reflection of the compatibility or noncompatibility of processes underlying response generation rather than a reflection of the involvement or noninvolvement of focal attention. Perhaps the generation of two detection responses (Experiment 1) or of a detection and a discrimination response (Experiments 3 and 4 ) poses fewer difficulties for the observer than does the generation of two discrimination responses (Experiment 2). However, this appears unlikely. A number of authors have observed interference with detection responses. Two detections of tilted targets among vertical nontargets (which were too distant to form a feature gradient) have been found to interfere (Duncan, 1985). Interference has also been reported for the discrimination of a cued letter target ( $\mathrm{T}$ or $\mathrm{L}$ ) and the simultaneous detection of a $\mathrm{T}$ among several L nontargets (Kröse \& Julesz, 1989). Several instances of interference between a discrimination and a detection task have been noted by Hoffman, Nelson, and Hough (1983).

\section{Could feature-gradient detection require a small fraction of the limited capacity?}

A second objection can be raised against our contention that, if the limited-capacity process engaged by our discrimination task would have participated in any way in our detection task, this would necessarily have revealed itself through a reduction in the performance of the latter task. It is certainly possible that our detection task is resource-limited in the sense of Norman and Bobrow (1975), and that even a partial availability of the limitedcapacity process is sufficient for performing this task at normal levels. In other words, it is possible that a total removal of the resources of focal attention would have prevented our detection task from being carried out, but that what we achieved was only a partial removal, which did not have this effect.

We attempted to meet this objection through several aspects of experimental design. Stimulus parameters (contrast, spatial frequency of target and background elements, 
element separation) were chosen to optimize the visibility of feature-gradient targets. A glance at Figure 1 will convince the reader that the pop-out effect obtained is strong. To counterbalance high stimulus visibility, considerable care was taken to create an effective masking pattern (mask contrast was twice the stimulus contrast, the spatial relationship between stimulus elements and mask elements was not constant, the mask was nonuniform and contained stronger feature gradients than did the stimulus, and a new mask was generated for every trial). These measures (i.e., the use of an easily visible stimulus and the sharp curtailment of stimulus persistence by effective masking) are expected to favor resourcelimited performance of a task (Norman \& Bobrow, 1975).

The minimal duration for which the stimulus had to persist for the subjects to reliably perform the detection task was comparable to, if not higher than, the persistence time required by our discrimination tasks (Tables 1-4). In other words, the absolute task difficulties were comparable. Any requirement by the detection task for a limited capacity was therefore likely to persist at least as long as the corresponding requirement of the discrimination tasks. That our discrimination tasks engaged a limited-capacity process for a span of time that is comparable to stimulus persistence was argued above. In addition, the handedness discrimination task used in Experiment 4 would be expected to pose a particularly severe demand on a limited resource, such as focal attention. It seems clear, therefore, that the outcome of Experiments 3 and 4 was obtained despite a nonquantifiable, but substantial, reduction, lasting throughout stimulus persistence, in the availability of the limited capacity engaged by our discrimination tasks. In a subsequent series of experiments (Braun \& Sagi, 1990), we have obtained similar outcomes despite an increase in the separation between discrimination and detection targets from $3^{\circ}$ to $6^{\circ}$ and despite placing the two types of targets in opposite visual hemifields.

Because none of these measures affected featuregradient performance, the most parsimonious explanation would seem to be that feature-gradient tasks do not involve the limited-capacity process under investigation.

\section{Are Experiments 2 and 3 comparable?}

A further objection is that differences between the stimuli for Experiment 2 and the stimuli for Experiment 3 make it difficult to judge the demand on a limited-capacity process posed by the discrimination task in these two experiments. The basis for this objection is the absence of background elements in Experiment 2 and the analogous experiment with handedness targets (which was not reported in full). As mentioned earlier, the reason for leaving out background elements was to exclude the possibility of a contribution from feature-gradient mechanisms to the performance of the secondary (eccentric) discrimination task. For the primary (central) discrimination task, the presence of flanking elements, as in Experiments 3 and 4 , is expected to increase, not decrease, the requirements of attention (e.g., LaBerge \& Brown, 1989). Ad- ditional experiments have confirmed, for both orientation and handedness discrimination, that the addition of background elements does not affect the demand for a limitedcapacity process posed by these tasks.

\section{Is focal attention the limited-capacity process under study?}

A fourth and final objection to the interpretation of our results is that the limited-capacity process that we have studied may not be identical to the postulated process that other authors have called "focal attention," "spatial attention," and so forth. In fact, we did not present any evidence for the fact that we study focal attention beyond the observation of competition between spatially separate targets under conditions of masking. We agree that there remains a need to establish focal attention as a unitary phenomenon, at least for cuing and masking paradigms, but note that extant evidence (e.g., Sagi \& Julesz, 1986), as well as general scientific procedure, would seem to favor a unitary explanation.

\section{CONCLUSIONS}

We have investigated the compatibility of two visual tasks that were attempted simultaneously: (1) a featuregradient task that exercises the subject's capability for perceiving salient boundaries and singularities in parallel across the entire visual scene, and (2) a task thought to engage focal attention. We have shown that such tasks do not interfere and can be accomplished simultaneously without adverse effect on either. Thus, the detection of a feature gradient was not affected by a reduction in the availability of visual attention.

Our results show that, over a considerable range of availability of the resources of focal attention, such resources are not a limiting factor for feature-gradient performance. This suggests strongly that focal attention does not participate in feature-gradient performance and that feature-gradient tasks can be carried out outside the region at which focal attention is engaged. Feature-gradient tasks thus seem to be mediated exclusively by nonattentive mechanisms.

If one accepts that the detection of feature gradients is not aided by focal attention, a number of important consequences follow. First, this would imply that the detection of salient boundaries and singularities in a visual scene constitutes a distinct class of nonattentive perceptions and would lay to rest the notion that attentive and nonattentive visual performance represent merely the opposite ends of a continuum (Bergen \& Julesz, 1983b; Eriksen \& St. James, 1986; Jonides, 1983; Treisman \& Gormican, 1988).

Second, it would suggest that observers have introspective access to, and are able to report attributes of, the nonattended parts of a visual scene. This would remove from focal attention any exclusive responsibility for the mediation of access to the processing levels at which a stimulus enters introspective awareness and at which a 
response is generated. In this context, it may or may not be significant that, while focal attention was engaged at fixation, the observers reported curious misperceptions of the eccentric parts of the stimulus pattern: they appeared introspectively larger, and their contrast seemed enhanced.

Such a reading of our results would, of course, contradict the suggestion of Duncan $(1980,1984,1985)$ that " no stimulus attribute can be overtly reported unless the target itself gains access to the limited-capacity system", and that "it is wrong to conclude that any attribute can be perceived 'without attention' ' (Duncan, 1985, p. 96). To the contrary, it would imply that such attributes as the presence and location of a feature-gradient target are perceived without attention.

Third, acceptance of this interpretation would open the possibility that information about salient boundaries and singularities gleaned by nonattentive processes may play a rather larger role in everyday vision than has been hitherto imagined. Such information could not only guide, or help to guide, the shifts of selective attention (e.g., Koch \& Ullman, 1985) but, so we speculate, in a thoroughly familiar environment, it could prove to be sufficiently rich to permit visual recognition.

Fourth, if unattentive and attentive visual mechanisms could function side by side, they should perhaps be thought of not as successive stages of vision, but rather as two visual faculties that operate concurrently and that provide us with complementary forms of access to the visual world.

If, in fact, we do enjoy vision outside the focus of attention with respect to certain prominent features of a stimulus, it will not necessarily be the case that all parallel visual performance is nonattentive. It remains possible that some visual tasks that are attentive (in the sense that their performance suffers when visual attention becomes less available) do not exhibit serial behavior to any marked degree. In other words, there may well be visual tasks that involve a dispersed form of attention. It appears that the consistent-mapping search task investigated by Hoffman, Nelson, and Houck (1983) and the detection task studied by Kröse and Julesz (1989) may be members of this category.

\section{REFERENCES}

BECK, J. (1972). Similarity grouping and peripheral discriminability under uncertainty. American Journal of Psychology, 85, 1-19.

Beck, J., Prazdny, K., \& Rosenfeld, A. (1983). A theory of textural segmentation. In J. Beck, B. Hope, \& A. Rosenfeld (Eds.), Human and machine vision (pp. 1-38). New York: Academic Press.

BERgen, J. R., \&Ulesz, B. (1983a). Parallel versus serial processing in rapid pattern discrimination. Nature, 303, 696-698.

BERGEN, J. R., \& Julesz, B. (1983b). Rapid discrimination of visual patterns. IEEE Transactions on Systems, Man, \& Cybemetics, SMC$13,857-863$.

BraUn, J., \& SAGI, D. (1989). Double response experiments show sharp preattentive-attentive dichotomy. Invesfigative Ophthalmology \& Visual Science, 30(Suppl.), 456.

Braun, J., \& SAGI, D. (1990). Texture-based tasks are little affected by a second task which requires peripheral or central attentive fixation. Manuscript submitted for publication.

Briand, K. A. Klein, R. M. (1987). Is Posner's beam the same as Treisman's glue? On the relation between visual orienting and feature integration theory. Journal of Experimental Psychology: Human Perception \& Performance, 13, 228-241.

Daugman, J. D. (1984). Spatial visual channels in the Fourier plane Vision Research, 24, 891-910.

Dick, M., Ullman, S., SAGI, D. (1987). Parallel and serial processes in motion detection. Science, 237, 400-402.

DUNCAN, J. (1980). The locus of interference in the perception of simultaneous stimuli. Psychological Review, 87, 272-300.

DUNCAN, J. (1984). Selective aftention and the organization of visual information. Journal of Experimental Psychology: General, 113, $501-517$.

Duncan, J. (1985). Visual search and visual attention. In M. I. Posner \& O. S. M Marin (Eds.), Attention and performance XI (pp. 85106). Hillsdale, NJ: Erlbaum.

Eriksen, C. W., Hoffman, J. E. (1973). The extent of processing of noise elements of selective encoding from visual displays. Perception \& Psychophysics, 14, 155-160.

Eriksen, C. W., Hoffman, J. E. (1974). Selective attention: Noise suppression or signal enhancement? Bulletin of the Psychonomic Society, 4, 587-589

ERIKSEN, C. W., \& ST. JAMES, J. D. (1986). Visual attention within and around the field of focal attention: A zoom lens model. Perception \& Psychophysics, 40, 225-240.

Eriksen, C. W., Webs, J. M. (1989). Shifting of attentional focus within and about a visual display. Perception \& Psychophysics, 45, 175-183.

Helmooltz, H. Von (1925). Physiological optics (Vol. 3). (J. P. C Southall, Ed. \& Trans.). Washington DC: Optical Society of America. (Original work published 1850)

HofFMAN, J. E. (1975). Hierarchical stages in the processing of visual information. Perception \& Psychophysics, 18, 348-354.

Hoffman, J. E., Nelson, B. (1981). Spatial selectivity in visual search. Perceprion \& Psychophysics, 30, 283-290.

Hofrman, J. E., Nelson, B., Houck, M. R. (1983). The role of attentional resources in automatic detection. Cognitive Psychology, 51, 379-410.

JAMEs, W. (1890). Principles of psychology I. New York: Holt.

JONIDES, J. (1983). Further toward a model of the mind's eye's movement. Bulletin of the Psychonomic Sociery, 21, 247-250.

JuLesz, B. (1981). Textons, the elements of texture perception, and their interactions. Nature, 290, 91-97.

JULESZ, B. (1984). Toward an axiomatic theory of preattentive vision. In G. M. Edelman, W. E. Gall, \& W. M. Cowan (Eds.), Dynamic aspects of neocortical function (pp. 585-612). New York: Neurosciences Research Foundation.

KoCh, C., \& Ullman, S. (1985). Shifts in selective visual attention: Towards the underlying neural circuitry. Human Neurobiology, 4, 219-227.

Kröse, B. J. A., \& JULEsz, B. (1989). The control and speed of shifts of attention. Vision Research, 29, 1607-1619.

LABERGE, D. (1983). Spatial extent of attention to letters and words. Journal of Experimental Psychology: Human Perception \& Performance, 9, 371-380.

LABERGE, D., \& Brown, V. (1989). Theory of attentional operations in shape identification. Psychological Review, 96, 101-124.

Murphy, T. D., ERIKSEN, C. W. (1987). Temporal changes in the distribution of attention in the visual field in response to precues. Perception \& Psychophysics, 42, 576-586.

Nakayama, K., Silverman, G. H. (1986). Serial and paraliel processing of visual feature conjunctions. Nature, 320, 264-265.

NeISSER, U. (1967). Cognitive psychology. New York: AppletonCentury-Crofts.

Norman, D. A., Bobrow, D. G. (1975). On data-limited and resource-limited processes. Cognitive Psychology, 7, 44-64.

Podgorny, P., \& ShePard, R. N. (1983). Distribution of visual attention over space. Joumal of Experimental Psychology: Human Perception \& Performance, 9, 380-393. 
PoSNER, M. I. (1980) Orienting of attention. Quarterly Journal of Experimental Psychology, 109, 160-174.

Posner, M. I., Snyder, C. R., Davidson, B. J. (1980). Attention and the detection of signals. Journal of Experimental Psychology: General, 2, 160-174.

Prinzmetal, W., Banks, W. P. (1983). Perceptual capacity limits in visual detection and search. Bulletin of the Psychonomic Society, 21, 263-266.

Prinzmetal, W., Presti, D. E., \& Posner, M. I. (1986). Does attention affect visual feature integration? Journal of Experimental Psychology: Human Perception \& Performance, 12, 361-369.

QUinlan, P. T., \& HuMPhreys, G. W. (1987). Visual search for targets defined by combinations of color, shape, and size: An examination of the task constraints on feature and conjunction searches. Perception \& Psychophysics, 41, 455-472.

Remington, R., \& Pierce, L. (1984). Moving attention: Evidence for time-invariant shifts of visual selective attention. Perception \& Psychophysics, 35, 393-399.

Rock, I., \& GUTMAN, D. (1981). The effect of inattention on form perception. Journal of Experimental Psychology: Human Perception \& Performance, 7, 265-285.

SAGI, D. (1988). The combination of spatial frequency and orientation is effortlessly perceived. Perception \& Psychophysics, 43, 601-603.

SAGI, D. (in press). Detection of an orientation singularity in Gabor textures: Effect of signal density and spatial frequency. Vision Research.

SAGI, D., \& JulEsz, B. (1985a). Fast noninertial shifts of attention. Spatial Vision, 2, 141-149.

SAGI, D., \& Julesz, B. (1985b). "Where" and "what" in vision. Science, 228, 1217-1219.

SAGI, D., JULESZ, B. (1986). Enhanced detection in the aperture of focal attention during simple discrimination tasks. Nature, 321, 693-695.

SAGI, D., JULESZ, B. (1987). Short-range limitation on detection of feature differences. Spatial Vision, 2, 39-49.

Schneider, W., \& Shiffrin, R. M. (1977). Controlled and automatic human information processing: I. Detection, search, and attention. Psychological Review, 84, 1-66.
Shiffrin, R. M., \& SChNeIder, W. (1977). Controlled and automatic human information processing: II. Perceptual learning, automatic attending, and a general theory. Psychological Review, 84, 127-190.

Shulman, G. L., Sheehy, J. B., Wilson, J. (1986). Gradients of spatial attention. Acta Psychologica, 61, 167-181.

Shulman, G. L., Wilson, J., Sheehy, J. B. (1985). Spatial determinants of the distribution of attention. Perception \& Psychophysics, $37,59-65$.

Treisman, A. (1985). Preattentive processing in vision. Computer Vision, Graphics, \& Image Processing, 31, 156-177.

Treisman, A., \& GelaDE, G. (1980). A feature integration theory of attention. Cognitive Psychology, 12, 97-136.

Treisman, A., \& Gormican, S. (1988). Feature analysis in early vision: Evidence from search asymmetries. Psychological Review, 95, 15-48.

TSAL, Y. (1983). Movements of attention across the visual field. Journal of Experimental Psychology: Human Perception \& Performance, 9. 523-530.

Ullman, S. (1984). Visual routines. Cognition, 18, 97-159.

\section{NOTES}

1. In the presence of background elements, localizing the eccentric target requires an additional step of processing that is performed by parallel mechanisms and that is not necessary in the case of the center target. Nevertheless, we have found that the basic outcome of the experiment (interference between the two tasks) remains the same with background elements (results not shown).

2. The use of orientation differences as the defining attribute of the target is apparently not critical to the outcomes reported here. We have obtained equivalent results in pilot studies, in which the target differed in spatial frequency or in lightness.

3. The experiments alluded to include the combination of a central and an eccentric handedness target, as well as the combination of a central handedness and an eccentric orientation target.

(Manuscript received June 8, 1989; revision accepted for publication January 1, 1990.) 